Special Issue: Agricultural Productivity and Sustainability Improvement in Tropical Region

\title{
Mass Production of Panax ginseng C.A. Mey. Root Cultures in Indonesia
}

\section{Stefan Pratama Chandra ${ }^{1}$, Yoanes Maria Vianney ${ }^{1}$, Theresia Liliani Christie ${ }^{2}$, Merlyn Wongso ${ }^{2}$, Melisa Widjaja ${ }^{2}$, Deok-Chun Yang ${ }^{3}$, Se Chan Kang ${ }^{4}$, Manar Fayiz Mousa Atoum ${ }^{5,6}$ and Johan Sukweenadhi ${ }^{*}$}

${ }^{1}$ Faculty of Biotechnology, University of Surabaya, Raya Kalirungkut, Surabaya 60293, Indonesia; ${ }^{2}$ PT. Bintang Toedjoe, Pulomas, Jakarta 13210, Indonesia; ${ }^{3}$ Graduate School of Biotechnology, College of Life Science, Kyung Hee University, Yonginsi, Gyeonggi-do 17104, Republic of Korea; ${ }^{4}$ Department of Oriental Biotechnology, College of Life Sciences, Kyung Hee University, Yongin-si, Gyeonggi-do 17104, Republic of Korea; ${ }^{5}$ Molecular Biology and Genetics, The Hashemite University, PO Box 330127, 13133 Zarqa, Jordan; ${ }^{6}$ Department of Medical Laboratory Sciences, The Hashemite University, Zarqa, Jordan.

Abstract | Panax ginseng C.A. Mey. is one of the most well-known plants in traditional medicine that contains bioactive compounds called ginsenosides. It is widely used as raw material in many pharmaceutical industries in Indonesia. However, to supply for this purpose, they still rely on imports. PT. Kalbe Farma (through its subsidiary, PT. Bintang Toedjoe), University of Surabaya (Ubaya), and Hanbang-Bio Laboratory (holding company of Kyung Hee University) established the Kalbe Ubaya Hanbang-Bio Laboratory (KUH Lab), a collaboration initiated to achieve the independence of raw materials. This laboratory is devoted to developing the plant tissue culture protocol for the mass production of $P$. ginseng root cultures. This paper is the first report of in vitro $P$. ginseng culture in Indonesia. The initial stage of the mass production focused on optimizing the culture conditions: inoculum weight $(100 \mathrm{~g}, 150 \mathrm{~g}, 200 \mathrm{~g})$, medium volume (12 L, $13 \mathrm{~L}, 14 \mathrm{~L})$, medium formulation ("A", "B"), and incubation temperature $\left(15^{\circ} \mathrm{C}\right.$ to $20^{\circ} \mathrm{C}$ and $21^{\circ} \mathrm{C}$ to $25^{\circ} \mathrm{C}$ ). Based on the biomass yield and ginsenosides content, it was concluded that the optimum growth condition was $150 \mathrm{~g}$ of the initial inoculum grown in $13 \mathrm{~L}$ of media using formulation $\mathrm{B}$ and incubation at $21^{\circ} \mathrm{C}$ to $25^{\circ} \mathrm{C}$. In the long-term, KUH Lab aims to produce $P$. ginseng on an industrial scale to sufficiently supply the demands for P. ginseng in the country. Furthermore, this laboratory also intends to make standardized Indonesian herbal materials by using plant tissue culture.

Received | June 12, 2021; Accepted | December 13, 2021; Published | December 28, 2021

*Correspondence | Johan Sukweenadhi, Faculty of Biotechnology, University of Surabaya, Raya Kalirungkut, Surabaya 60293, Indonesia; Email: sukwee@staff.ubaya.ac.id

Citation | Chandra, S.P., Y.M. Vianney, T.L. Christie, M. Wongso, M. Widjaja, D.C. Yang, S.C. Kang, M.F.M. Atoum and J. Sukweenadhi. 2021. Mass Production of Panax ginseng C.A. Mey. Root Cultures in Indonesia. Sarbad Journal of Agriculture, 37(Special issue 1): $98-109$.

DOI | https://dx.doi.org/10.17582/journal.sja/2021/37.s1.98.109

Keywords | Ginseng, Ginsenosides, In vitro, Medicine plant, Tissue culture

\section{Introduction}

Panax ginseng C.A. Mey. is one of the most common ginseng species used in the community. P. ginseng can be found in several countries, such as Korea (common name: Insam), China (common name: Rénshèn), and Japan (common name Ninjin). It has gained importance in traditional medicine because it can restore fatigue (Mahady et al., 2000). Panax means "all-healing", which comes from the belief that ginseng can cure all diseases in humans. Its benefits include modulating various ion channels 
and signal transduction, increasing blood circulation, antioxidants, blood pressure, etc and tumor suppression (Kim, 2018). For these reasons, the market demand for product variants of $P$. ginseng is increasing. Still, cultivated ginseng roots are considerably high-priced because they can take $4 \mathrm{yr}$ to $6 \mathrm{yr}$ to be ready for harvest.

The main bioactive compounds found in $P$ ginseng are ginsenosides (Yu et al., 2019). Based on chemical structure, ginsenosides can be divided into two major groups, namely protopanaxadiol (PD) and protopanaxatriol (PT) (Sengupta et al., 2004). Ginsenosides reportedly have antimicrobial, antifungal, and even anti-cancer properties. In addition, they can cure cardiovascular (Kim, 2018) and neurological diseases (Gantait et al., 2020). To date, more than 200 ginsenosides have been identified, including the major (e.g., Rb1, Rb2, Rc, Rd, Re, Rg1) and minor ginsenosides (e.g., Rg3, Rh1, Rh2) (Christensen et al., 2006; Qi et al.,2011). Ginsenosides are widely used for pharmaceuticals in European countries and retail products in American countries (Kim et al., 2013).

Plant tissue culture is an alternative method of producing high-value secondary metabolites. It is a technique of growing a plant organ in vitro on a particular medium that involves incubation in a sterile and controlled condition. Usually, plants grown with tissue culture have high functional values, difficult conventional cultivation, and low yield percentages (Melviana et al., 2021a). However, plant tissue culture offers several advantages compared with traditional cultivation techniques. They are not dependent on geographic location, and climate can provide a system to produce bioactive plants or compounds with consistent quality and yield and can eliminate factors that potentially reduce the production of bioactive compounds (such as pathogens and other stress factors) (Melviana et al. 2021b; Smetanska, 2008). Another advantage is that the plants can be produced free from harmful chemicals, such as herbicides, pesticides, insecticides, and microbial infections. As a result, they will have a higher yield than the plants grown in nature and contaminated with microorganisms (Gulzar et al., 2020).

Several in vitro approaches that can be used to produce ginsenoside are shoot culture, callus culture, cell suspension culture, protoplast culture, bioreactor scale propagation, in vitro mutagenesis, polyploidization induction, hairy roots, and root culture (Young et al., 2001). Root culture has many advantages over other in vitro methods: it enables a stable growth phase, is genetically stable, and can produce secondary metabolites in the same or even higher level than the organ that is not transformed (Gantait et al., 2020).

The main ginsenoside production organ in $P$. ginseng is the roots. Currently, some ginsenosides have been successfully obtained from other organs of $P$. ginseng, such as the Ginsenosides AP (arabinopyranoside) derived from flower buds. To overcome the long cultivation period and its risks, propagation methods are used in plant tissue cultures, including root cultures (Gantait et al., 2020). P. ginseng is widely used in the pharmaceutical industry in Indonesia. However, $90 \%$ of this raw material relies on imports. Therefore, PT. Kalbe Farma, through its subsidiary, PT. Bintang Toedjoe, collaborated with the University of Surabaya (Ubaya) and Hanbang-Bio Laboratory from Kyung Hee University, South Korea, in initiating efforts to reduce imports of the raw material by establishing the Kalbe Ubaya Hanbang-Bio Laboratory (KUH Lab). This laboratory is devoted to optimizing the P. ginseng root culture on a bioreactor scale in the country. The initial stage of the production is to optimize several factors affecting growth and ginsenoside accumulation, namely inoculum weight, growth medium volume, incubation period, and incubation temperature.

These four factors were optimized in the KUH Lab by experimenting with a few variations: $100 \mathrm{~g}, 150 \mathrm{~g}$, $200 \mathrm{~g}$ of inoculum; $12 \mathrm{~L}, 13 \mathrm{~L}, 14 \mathrm{~L}$ of the growth medium; "A" and "B" formulations; and incubation at $15^{\circ} \mathrm{C}$ to $20^{\circ} \mathrm{C}$ and $21^{\circ} \mathrm{C}$ to $25^{\circ} \mathrm{C}$. The effect of each variation on several parameters was observed, such as fresh weight, dry weight, yield, and water content of the root cultures. Based on the statistical test results, the optimal procedure for large-scale production of $P$. ginseng root cultures involves inoculating $150 \mathrm{~g}$ of fresh roots into $12 \mathrm{~L}$ of growth medium prepared with formulation " $\mathrm{B}$ " and incubating the inoculum at $21{ }^{\circ} \mathrm{C}$ to $25^{\circ} \mathrm{C}$ for $7 \mathrm{wk}$ (weeks). In the long-term, this laboratory plans to produce $P$. ginseng on an industrial scale to sufficiently meet the demands for this plant in Indonesia and manufacture many standardized Indonesian herbal materials using plant tissue culture.

\section{Materials and Methods}

The root cultures used in this study were obtained 
from the Hanbang-Bio Laboratory, Kyung Hee University, in South Korea.

\section{Procedures of large-scale production of Panax ginseng root cultures}

Large-scale production was carried out in an $18 \mathrm{~L}$ bioreactor (BR-BIO180, Hanbang-Bio Inc., South Korea) made of polycarbonate with a maximum content capacity of $15 \mathrm{~L}$. It was specifically molded to connect the main body of the bioreactor to a sparger (bottom) and vent system (upper part). Meanwhile, the air supply was infused and discharged through a silicon tube $(\Phi 7 \mathrm{~mm})$ with a clean filter $(0.2 \mu \mathrm{m})$. The bioreactor was connected to a separate air pump system.It was filled with $12 \mathrm{~L}$ of Reverse Osmosis (RO) water using Pure RO II. The media concentrate with formulation " $\mathrm{A}$ " was added to the water-filled bioreactor (final volume $13 \mathrm{~L}$ ). The bioreactor was sterilized in an autoclave (Hankuk HK-AC200P) at $121{ }^{\circ} \mathrm{C}$ for $70 \mathrm{~min}$ at a pressure of $1.5 \mathrm{~atm}$. The bioreactor was kept for at least $4 \mathrm{~d}$ before use to cool down and confirm the absence of contaminants. A total of $150 \mathrm{~g}$ of roots were inoculated into the bioreactor. Then, the bioreactor was connected to an air compressor to provide continuous aeration and agitation until harvest. The root culture was incubated at $21^{\circ} \mathrm{C}$ to $25^{\circ} \mathrm{C}$ for 7 wk at $40 \%$ to $50 \%$ humidity.

\section{Procedure optimization for bioreactor-scale production of} Panax ginseng root cultures

The optimized variables were inoculum weight, medium volume, medium formulation, and incubation temperature. The inoculum weights were made with three-part variation: $100 \mathrm{~g}, 150 \mathrm{~g}$, and $200 \mathrm{~g}$ fresh weight roots; each was inoculated into a $13 \mathrm{~L}$ medium prepared with formulation " $\mathrm{A}$ ". Then, the roots were incubated at $21^{\circ} \mathrm{C}$ to $25^{\circ} \mathrm{C}$ for seven weeks. The variation in the medium volume refers to the volume of water $(11 \mathrm{~L}, 12 \mathrm{~L}, 13 \mathrm{~L})$ used to dilute the concentrate with the same volume, $1 \mathrm{~L}$. Afterward, each was inoculated with $150 \mathrm{~g}$ of roots. The roots were then incubated at $21^{\circ} \mathrm{C}$ to $25^{\circ} \mathrm{C}$ for $7 \mathrm{wk}$. There were two types of medium formulations: " $\mathrm{A}$ " and " $\mathrm{B}$ "; each was inoculated with $150 \mathrm{~g}$ of roots. Basically, both formulations were the same liquid medium, i.e., modified Schenk and Hildebrandt (SH) medium, with the letters " $\mathrm{A}$ " and " $\mathrm{B}$ " marking the different types of auxin used. The roots were incubated at $21^{\circ} \mathrm{C}$ to $25^{\circ} \mathrm{C}$ for $7 \mathrm{wk}$. The incubation temperature was also tested using two-part variation: $15^{\circ} \mathrm{C}$ to $20{ }^{\circ} \mathrm{C}$ and $21{ }^{\circ} \mathrm{C}$ to $25^{\circ} \mathrm{C}$. A total of $150 \mathrm{~g}$ of roots were inoculated into a 13L medium with formulation " $\mathrm{A}$ " and then incubated at $15^{\circ} \mathrm{C}$ to $20^{\circ} \mathrm{C}$ and $21^{\circ} \mathrm{C}$ to $25^{\circ} \mathrm{C}$ for $7 \mathrm{wk}$. For all variable analyses, the air humidity of the culture room was uniform, namely $40 \%$ to $50 \%$.

\section{Harvest and drying of Panax ginseng root cultures}

After the incubation period was over, the roots were harvested. The medium was first removed, then the root culture was collected and placed in a container. After rinsing with tap water three times, the roots were rinsed again using $\mathrm{RO}$ water once. Then, they were drained in a perforated container for $1 \mathrm{~h}$ to minimize the amount of water on the roots and then put into a storage container. The roots were dried in a universal oven (Memmert UF750) set at $60{ }^{\circ} \mathrm{C}, 60 \%$ fan, and $60 \%$ air flap, and the duration was adjusted to the fresh weight of the cultured roots. Afterward, the dried roots were weighed using Mettler Toledo MS16001L. The dry weight data were used to calculate the percentage yield using the Formula (1):

$$
\% \text { Yied }=\frac{\text { Dry Weight }}{\text { Fresh Weight }} \ldots .
$$

Afterward, $3.7 \mathrm{~g}$ of the dried roots were inserted into a moisture analyzer (150 Sartorius) and then left to stand at $105{ }^{\circ} \mathrm{C}$ for $30 \mathrm{~min}$ to measure their water content. The water content was read three times (Vog1 and Ostermann, 2006).

\section{Extraction and sample preparation of Panax ginseng root cultures}

The dried roots were extracted using the Soxhlet method. Five $\mathrm{g}$ of dried roots were extracted in 300 $\mathrm{mL}$ of $80 \%$ methanol for $2 \mathrm{~h}$. Then, the extract of the roots was dried in a rotary evaporator (Rotavapor R-300, Buchi, German). The dry extract was dissolved in $20 \mathrm{~mL}$ of RO water then extracted again in watersaturated butanol in a ratio of $1: 1$. This mixture was centrifuged at $8000 \mathrm{rpm}(1 \mathrm{rpm}=1 / 60 \mathrm{~Hz})$ for $15 \mathrm{~min}$, and then the organic phase was collected and put into a $250 \mathrm{~mL}$ flask. Extraction with water-saturated butanol continued until the organic phase became clear. The butanol extract was evaporated again in a rotary evaporator (Rotavapor R-300, Buchi, German) to produce a dry extract without butanol scent.

\section{Ginsenosides analysis}

Samples were analyzed with a high-performance liquid chromatography instrument (HPLC, Agilent 1260 Infinity II). The dry extract was dissolved in $50 \mathrm{~mL}$ 
of HPLC-grade methanol then filtered with a $0.2 \mu \mathrm{m}$ PTFE filter. The stationary phase was Kinetex C18 with the dimension $50 \mathrm{~mm} \times 4.6 \mathrm{~mm}$, while the mobile phase was an eluent with acetonitrile (A)/water gradient. In the gradient elution, the composition of the mobile phase was set as follows: $7 \mathrm{~min}$ at $19 \%$ A (isocratic); $7 \mathrm{~min}$ to $11 \mathrm{~min}$ from $19 \%$ to $29 \%$ A (isocratic), $11 \mathrm{~min}$ to $14 \mathrm{~min}$ at $29 \% \mathrm{~A}$ (isocratic); $30 \mathrm{~min}$ to $31.5 \mathrm{~min}$ from $70 \%$ to $90 \% \mathrm{~A} ; 31.5 \mathrm{~min}$ to $34 \mathrm{~min}$ at $90 \% \mathrm{~A}$ (isocratic); $34 \mathrm{~min}$ to $34.5 \mathrm{~min}$ from $90 \%$ to $19 \% \mathrm{~A} ; 34.5 \mathrm{~min}$ to $45 \mathrm{~min}$ at $19 \% \mathrm{~A}$ (isocratic). Amount $5 \mu \mathrm{L}$ of the sample was injected

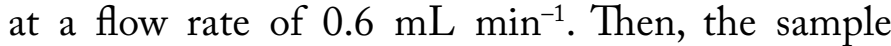
absorbance was read using a Diode Array Detector (DAD) at a wavelength of $203 \mathrm{~nm}$. The results were analyzed quantitatively by comparing the peak area of the sample with that of the reference standard.

\section{Statistical analysis}

Experiments of the growth factors were conducted separately in this order: inoculum weight, medium volume, medium formulation, and then incubation temperature. All data were analyzed statistically with IBM SPSS v. 25 software. One-Way ANOVA was used if the data were normal and homogeneous (parametric test). In contrast, the Kruskal-Wallis test was used if they were not normal or homogeneous (non-parametric test). A significant difference in the data was indicated by a $p$-value $<0.05 \%$ (Adinurani, 2016).

\section{Results and Discussion}

\section{Effect of various inoculum weights on Panax ginseng root} cultures

In large-scale production of root cultures, several important factors can affect biomass growth and accumulation of bioactive compounds, namely the root's genetic factors (Khan et al., 2015), growth media, other physical factors like incubation temperature (Wang et al., 2019), and inoculum weight (inoculum density) (Manuhara et al., 2015; Than et al., 2004). Because of differences in climatic and topographic conditions between Indonesia and South Korea and increasing biomass and ginsenoside accumulation, it is necessary to re-optimize several production procedures, including inoculum weight, media volume, media composition, and incubation temperature.

Inoculum weight is one of the factors that can influence the development of Panax ginseng root cultures. If the inoculum is light, the cell growth will be slow; conversely, the cell culture will grow relatively fast without experiencing a lag phase (Than et al., 2004). In this experiment, the inoculum weights were $100 \mathrm{~g}, 150 \mathrm{~g}$, and $200 \mathrm{~g}$, with $150 \mathrm{~g}$ acting as a control experiment. Figure 1 shows the effects of these weights on the properties of the root cultures and extracts: fresh weight, dry weight, yield, water content, and ginsenoside content.

The fresh weights of the root cultures produced by $100 \mathrm{~g}, 150 \mathrm{~g}$, and $200 \mathrm{~g}$ of inoculum were $1472.21 \mathrm{~g}$ $\pm 263.749 \mathrm{~g}, 1528.77 \mathrm{~g} \pm 361.539 \mathrm{~g}, 1508.92 \mathrm{~g} \pm$ $326.245 \mathrm{~g}$, respectively. Based on the statistical analysis results of this parameter, the roots produced with $150 \mathrm{~g}$ of inoculum had the heaviest fresh weight. Still, it was not significantly different from the effects of other inoculum weights (100 g and $200 \mathrm{~g}$ ). This result contradicts the study conducted by Srivastava and Srivastava (2007), which confirmed that a heavy inoculum could increase cell growth. However, it corresponds to Lee et al. (2006), who found that $60 \mathrm{~g} \mathrm{~L}^{-1}$ of inoculum could significantly increase the growth of Gymnema sylvestre $\mathrm{R}$. Br. culture. Still, inoculum heavier than $60 \mathrm{~g} \mathrm{~L}^{-1}$ led to a less significant increase in growth. Another factor that increases the fresh weight is the cutting process before inoculum is subcultured into media. Some areas are injured when the roots are cut, creating space for new branches to grow during the culture.

The dry weights of the root cultures produced by $100 \mathrm{~g}, 150 \mathrm{~g}$, and $200 \mathrm{~g}$ of inoculum were $88.12 \mathrm{~g} \pm$ $16.454 \mathrm{~g}, 97.02 \mathrm{~g} \pm 26.046 \mathrm{~g}$, and $97.95 \mathrm{~g} \pm 27.100 \mathrm{~g}$, respectively. Based on the statistical analysis results, the roots produced by $200 \mathrm{~g}$ of inoculum had the heaviest dry weight. However, it was not significantly different from the effects of other inoculum weights. Compared with $200 \mathrm{~g}$ of inoculum, the dry weight yielded by $150 \mathrm{~g}$ of inoculum was slightly lower. This result is common in dried roots, in which the drying process can affect the resultant dry weight depending on the duration; the duration of drying itself is determined by fresh weight and water content. Prolonged drying can remove more water from the roots, resulting in low dry weight, evidenced by the yield percentage and water content.

The yield percentage produced by $100 \mathrm{~g}, 150 \mathrm{~g}$, and $200 \mathrm{~g}$ of inoculum were $5.99 \% \pm 0.337 \%, 6.33 \% \pm$ $0.562 \%$, and $6.42 \% \pm 0.509 \%$, respectively, while the 

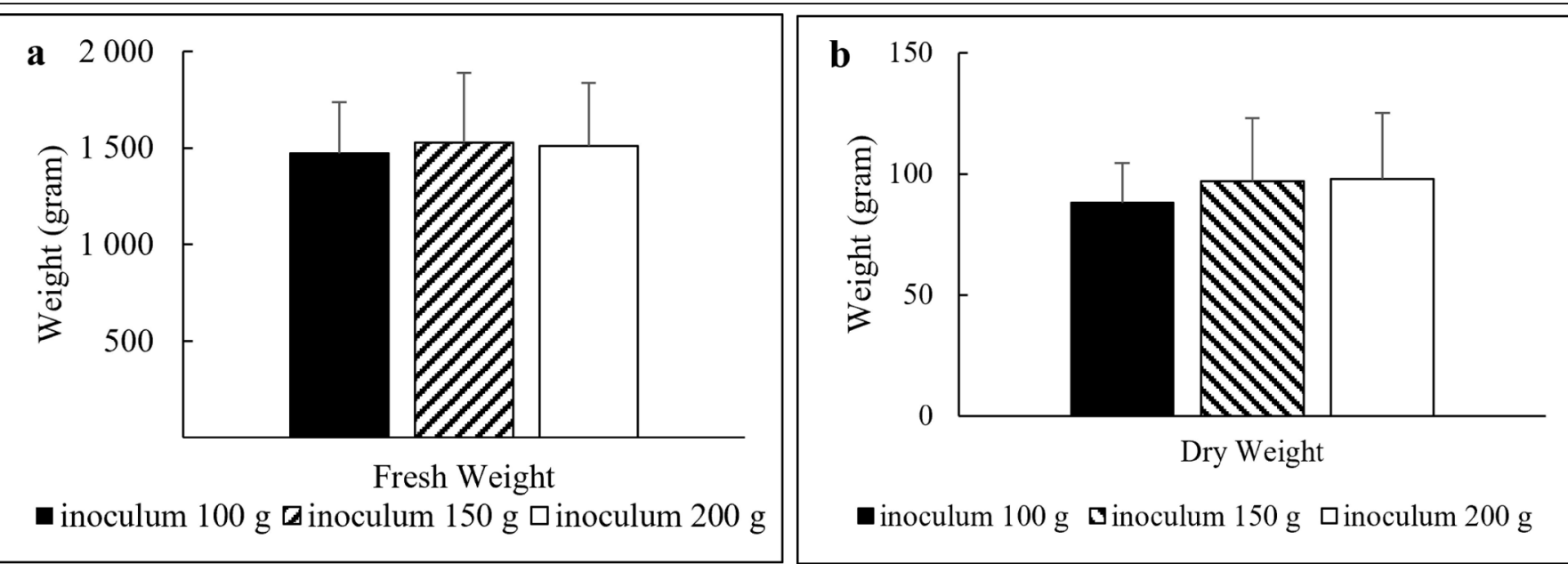

-inoculum $100 \mathrm{~g}$ Dinoculum $150 \mathrm{~g}$ 口inoculum $200 \mathrm{~g}$
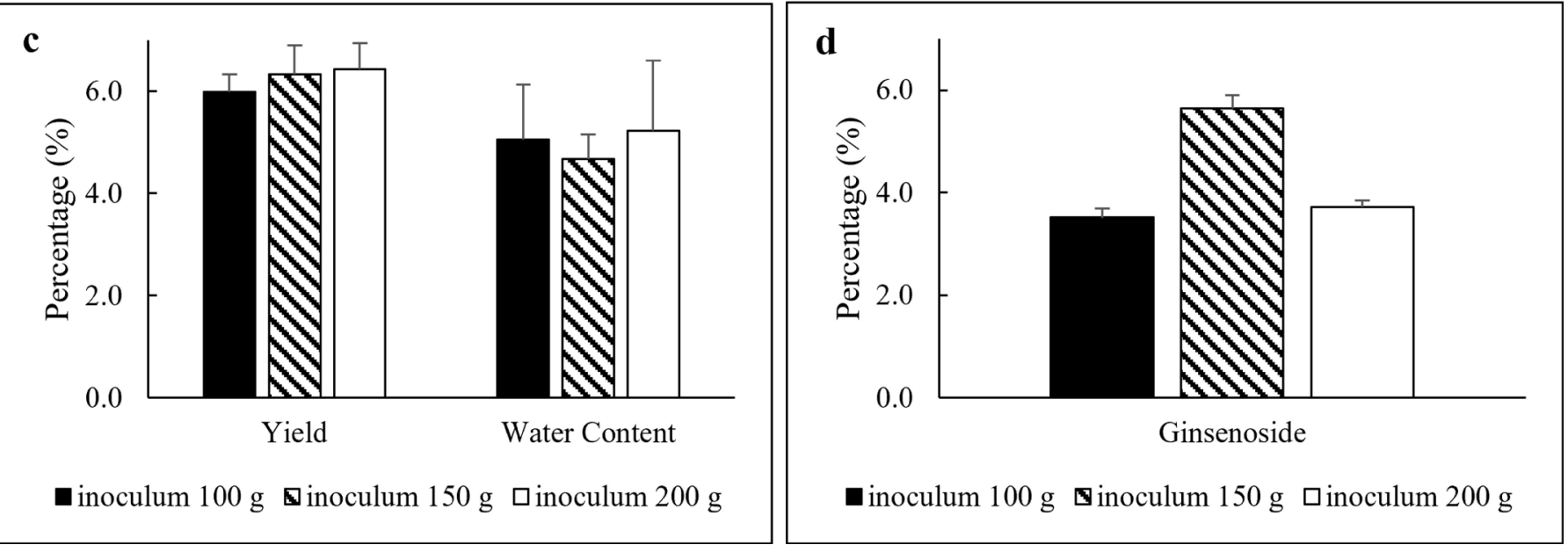

Figure 1: Bar chart of the effect of inoculum weight on a) fresh weight, $b$ ) dry weight, c) yield percentage and water content, and d) ginsenoside content. Values are means $\pm S D(n>3)$. Based on the One-Way ANOVA, there was no significant difference in each parameter $(P<0.05 \%)$.

water contents of the roots were $5.05 \% \pm 1.081 \%$, $4.67 \% \pm 0.490 \%$, and $5.22 \% \pm 1.387 \%$. These yield percentages and water contents were not significantly different among the inoculum weights. The water content of dried roots with $150 \mathrm{~g}$ of inoculum was lower than that of $100 \mathrm{~g}$ and $200 \mathrm{~g}$. Low water content can increase the material's shelf life because it inhibits microbial growth and enzyme activity (Lech et al., 2017). According to Arifin et al. (2006), the water content in dry materials should not be more than $10 \%$.

The ginsenoside contents of the root extracts made of $100 \mathrm{~g}, 150 \mathrm{~g}$, and $200 \mathrm{~g}$ of inoculum were $3.51 \%$ $\pm 0.170 \%, 5.64 \% \pm 0.252 \%$, and $3.72 \% \pm 0.126 \%$, respectively. In a study conducted on Morinda citrifolia L. root cultures, low inoculum weight can increase levels of bioactive compounds, such as anthraquinones, phenolics, and flavonoids (Baque et al., 2013). Based on the analysis results of each parameter, it can be concluded that the inoculum produces root cultures and extracts with favorable properties when added to the production at the weight of $150 \mathrm{~g}$.
Effects of various growth medium volumes on Panax ginseng root cultures

The availabilityofmacronutrientsand micronutrientsin growth media can affect plant growth and development and the accumulation of bioactive compounds. In this experiment, variations were made on the volume of water used for the liquid medium, namely $11 \mathrm{~L}$, $12 \mathrm{~L}$, and $13 \mathrm{~L}$. Meanwhile, the concentration and volume of the medium concentrate added for each variation were the same. Therefore, the total medium volumes were $12 \mathrm{~L}(11+1 \mathrm{~L}), 13 \mathrm{~L}(12+1 \mathrm{~L})$, and $14 \mathrm{~L}(13+1 \mathrm{~L})$, with the medium volume of $13 \mathrm{~L}$ being the control experiment. Figure 2 depicts the effects of variation in the medium volume on the parameters, such as fresh weight, dry weight, yield, water content, and ginsenoside content.

Based on the One-Way ANOVA, the fresh weights, dry weights, yield percentages, and water contents of the root cultures from the three medium volumes were not significantly different. However, the ginsenoside contents of the root cultures made in $12 \mathrm{~L}$ and $14 \mathrm{~L}$ media were significantly different from control. 

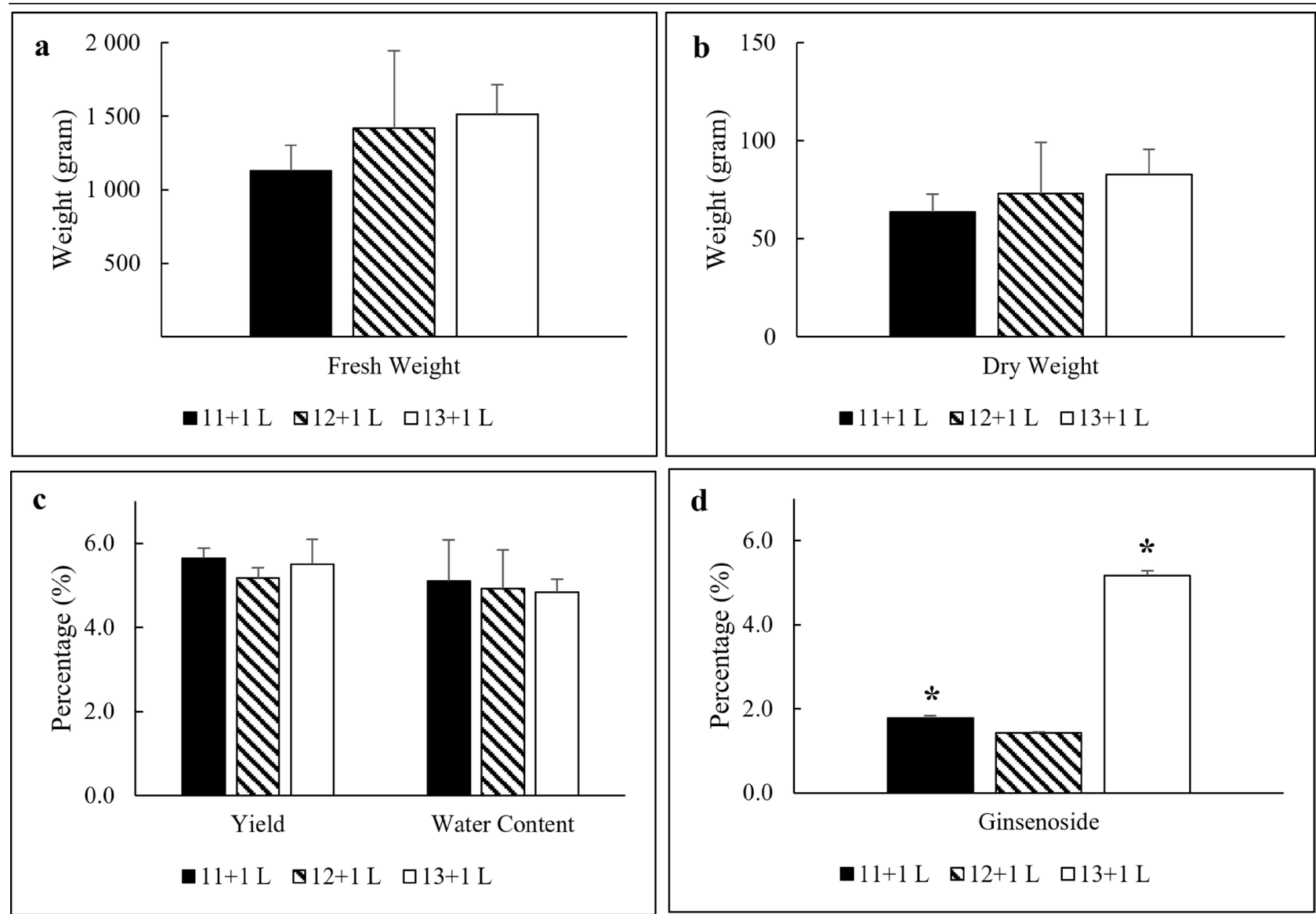

Figure 2: Bar chart of the effect of medium volume on a) fresh weight, b) dry weight, c) yield percentage and water content, and d) ginsenoside content. Values are means $\pm S D(n=3)$. Significant differences are marked with $\left(^{*}\right)$ and $\left({ }^{* *}\right)(P<0.05 \%$ and $P<0.01 \%$, respectively).

The fresh weights of the roots grown in the medium volumes of $12 \mathrm{~L}, 13 \mathrm{~L}$, and $14 \mathrm{~L}$ were $1128 \mathrm{~g} \pm$ $172.218 \mathrm{~g}, 1420.433 \mathrm{~g} \pm 525.689 \mathrm{~g}$, and $1513.433 \mathrm{~g}$ $\pm 201.479 \mathrm{~g}$, respectively. The statistical tests of this parameter revealed that the fresh weights produced by each volume were not significantly different from one another even though the $14 \mathrm{~L}$ medium made the heaviest fresh weight. Reducing the volume to $12 \mathrm{~L}$ negatively affected root growth, which can be attributed to osmotic stress because the growth media is more concentrated than the other two variations. Osmotic stress decelerates root growth but can accumulate more bioactive compounds (Akula and Ravishankar, 2011). A decrease in the fresh weight of the roots cultured in a $12 \mathrm{~L}$ medium is expected to be followed by an increase in ginsenoside accumulation. The $14 \mathrm{~L}$ medium produced roots with a slightly heavier fresh weight than $13 \mathrm{~L}$. This result, however, contradicts the theory in that dilution depletes the nutrient contents in growth media; thus, there should be a decrease in the growth rate due to fewer macronutrients and micronutrients (Prinzenberg et al., 2010). On the other hand, a nutritional deficiency can increase the accumulation of bioactive compounds, meaning that the $14 \mathrm{~L}$ medium will produce high ginsenoside levels.

The dry weights produced in the medium volumes of $12 \mathrm{~L}, 13 \mathrm{~L}$, and $14 \mathrm{~L}$ were $63.63 \mathrm{~g} \pm 9.333 \mathrm{~g}, 73.03 \mathrm{~g} \pm$ $26.019 \mathrm{~g}$, and $82.93 \mathrm{~g} \pm 12.606 \mathrm{~g}$, respectively. Based on the statistical analysis results, the medium volume variation did not lead to significantly different dry weights. The $14 \mathrm{~L}$ medium produced roots with the heaviest dry weight and fresh weight.

The yield percentages of root cultures in the medium volumes of $12 \mathrm{~L}, 13 \mathrm{~L}$, and $14 \mathrm{~L}$ were $5.65 \% \pm 0.237 \%$, $5.18 \% \pm 0.241 \%$, and $5.50 \% \pm 0.595 \%$, respectively, while the water contents were $5.10 \% \pm 0.978 \%, 4.92 \%$ $\pm 0.925 \%$, and $4.83 \% \pm 0.313 \%$. The statistical analysis discovered that the yield percentages and water contents did not significantly differ among the variations. The ginsenoside contents of the root extracts from the medium volumes of $12 \mathrm{~L}, 13 \mathrm{~L}$, and $14 \mathrm{~L}$ were $1.78 \% \pm 0.049 \%, 1.42 \% \pm 0.025 \%$, and $5.17 \% \pm 0.114 \%$, respectively. Based on the statistical 

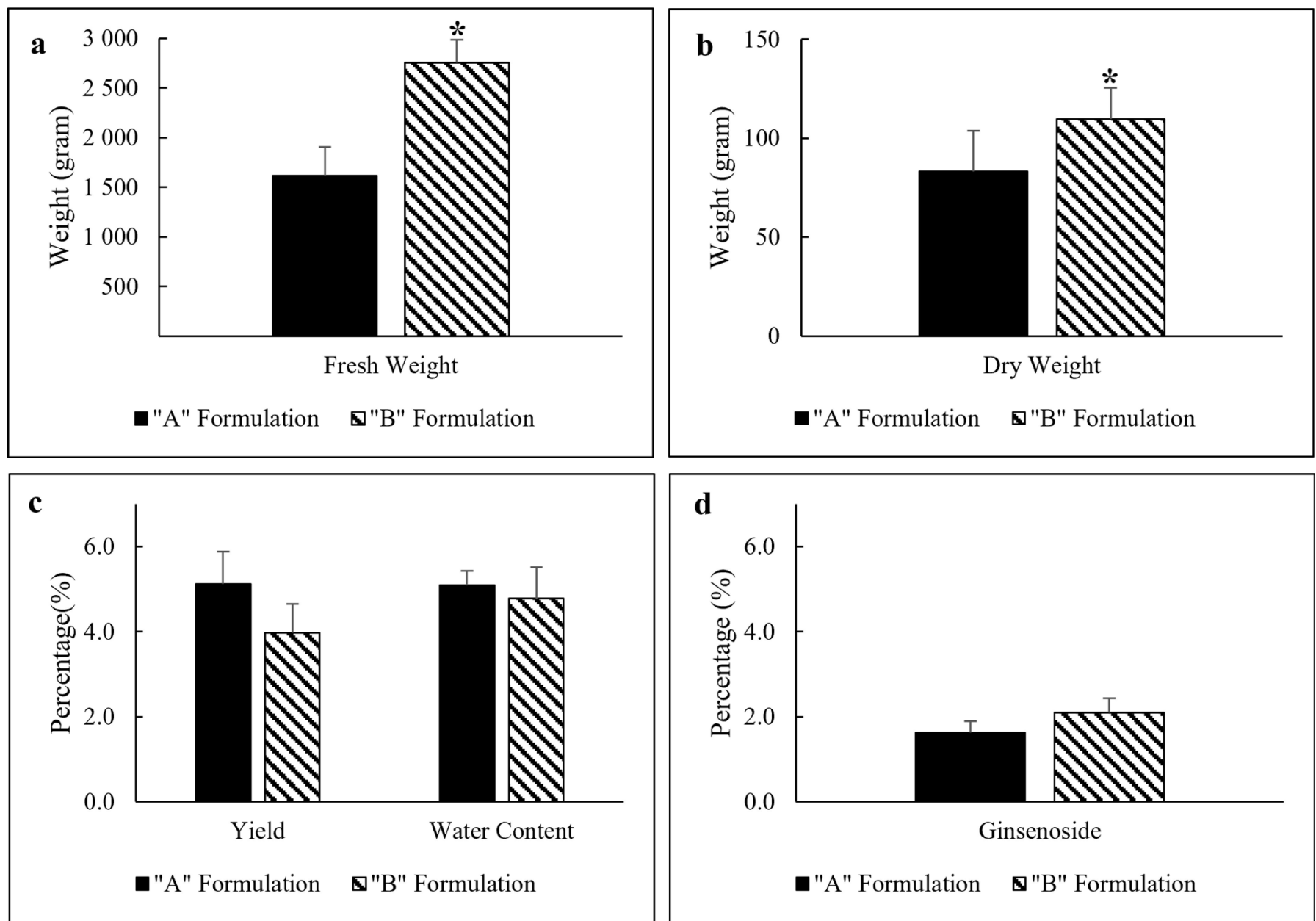

Figure 3: Bar chart of the effect of medium formulation on a) fresh weight, b) dry weight, c) yield percentage and water content, and d) ginsenoside content. Values are means $\pm S D(n>3)$.

analysis results, the ginsenoside levels produced by each medium volume differed significantly from one another. The $12 \mathrm{~L}$ medium produced root extracts with significantly higher ginsenoside content than $13 \mathrm{~L}$, and the $14 \mathrm{~L}$ medium produced those containing significantly higher ginsenosides than $12 \mathrm{~L}$ and 13 L. It can be concluded that osmotic stress and nutritional deficiency can increase the accumulation of ginsenosides. The analysis of each parameter revealed that $14 \mathrm{~L}$ of growth medium results in favorable properties for large-scale production of root cultures (optimal procedure).

Effects of various plant growth regulators on Panax ginseng root cultures

Medium formulations also play an essential role in the growth and accumulation of bioactive compounds in a plant. Using different auxin hormones, such as IAA, IBA, and NAA can cause differences in the rate of root formation (Sevik and Guney, 2013; Khan et al., 2021). In this experiment, formulations "A" and "B" were the same liquid medium but different hormones. "A" acted as a control, while "B" had variations in its formulation. The effects of varying medium formulations on the parameters, i.e., fresh weight, dry weight, \%yield, moisture content, and ginsenoside content, are presented in Figure 3.

Based on the One-way ANOVA, there were significant differences in the fresh weight, dry weight, and yield percentage between the medium formulations, as marked with $\left(^{*}\right)(P<0.05 \%)$. However, there was no significant difference in the water and ginsenoside contents for each medium formulation.

The fresh weights of the roots grown with the medium formulations " $\mathrm{A}$ " and "B" were $1614.97 \mathrm{~g} \pm$ $292.223 \mathrm{~g}$ and $2753.30 \mathrm{~g} \pm 231.343 \mathrm{~g}$. The statistical analysis results showed that the roots grown with the medium formulation " $\mathrm{B}$ " had significantly higher fresh weight than those cultured with "A". From these results, it can be concluded that " $\mathrm{B}$ " is more suitable for roots production. The dry weights produced using the medium formulations " $\mathrm{A}$ " and "B" were $83.07 \mathrm{~g} \pm$ 
$20.645 \mathrm{~g}$ and $109.76 \mathrm{~g} \pm 15.599 \mathrm{~g}$, respectively. Based on the statistical analysis results, the medium formulated with "B" produced roots with significantly higher dry weights than " $\mathrm{A}$ ". This was because roots cultured with "B" had a higher fresh weight than "A".

The yield percentages produced using formulations " $\mathrm{A}$ " and "B" were $5.12 \% \pm 0.766 \%$ and $3.98 \% \pm 0.345 \%$, while the water contents were $5.09 \% \pm 0.670 \%$ and $4.77 \% \pm 0.745 \%$. The statistical analysis results showed that the yield percentage produced using "B" was significantly lower than "A", which is interesting because with " $B$ " producing a higher dry weight, it can be expected to have a lower yield percentage. This result is thought to be caused by the hormones contained in "B" that cause the roots to have less water content than " $\mathrm{A}$ ", although their water contents did not differ significantly. Low water content makes the roots dry more quickly, thus affecting the yield percentage.

The extracts of the roots grown with formulations " $\mathrm{A}$ "
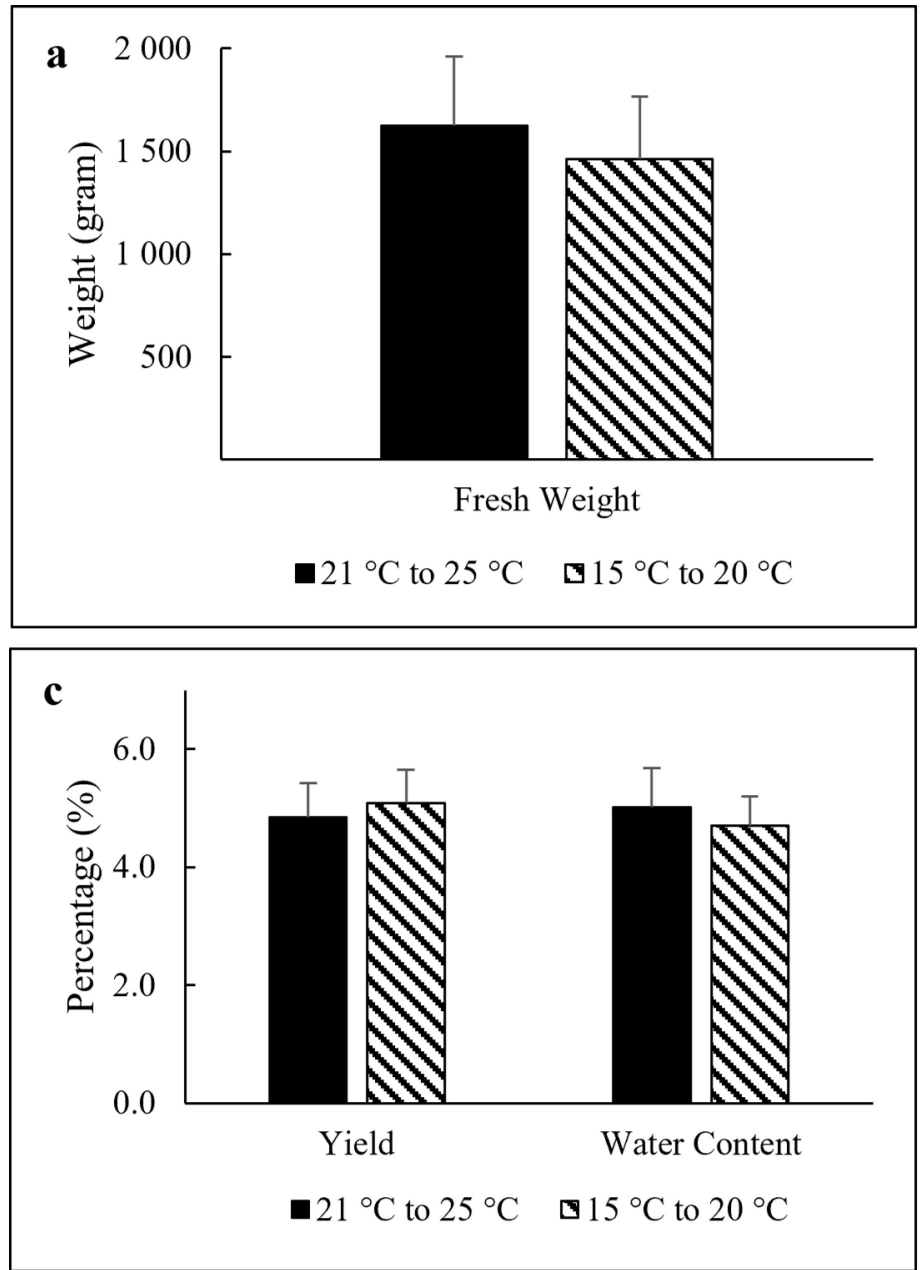

and "B" had ginsenoside contents of $1.63 \% \pm 0.264 \%$ and $2.10 \% \pm 0.331 \%$, respectively. Based on the statistical analysis, culturing roots with the medium formulation " $\mathrm{A}$ " or "B" did not produce extracts with significantly different ginsenoside levels. Overall, the analysis results of each parameter revealed that " $B$ " provides the optimal formulation for the large-scale production of $P$. ginseng root cultures.

\section{Effect of incubation temperature on Panax ginseng root cultures}

External environmental factors during the incubation (e.g., irradiation, temperature, and humidity) can affect the development and accumulation of bioactive compounds. Temperature partially causes abiotic stress that can hinder plant growth (Amir et al., 2017). In this experiment, the incubation temperature was set at two different ranges: $21^{\circ} \mathrm{C}$ to $25^{\circ} \mathrm{C}$ and $15^{\circ} \mathrm{C}$ to $20{ }^{\circ} \mathrm{C}$, with the former acting as a control. Figure 4 shows the effect of incubation temperature on the properties of root cultures and extracts.
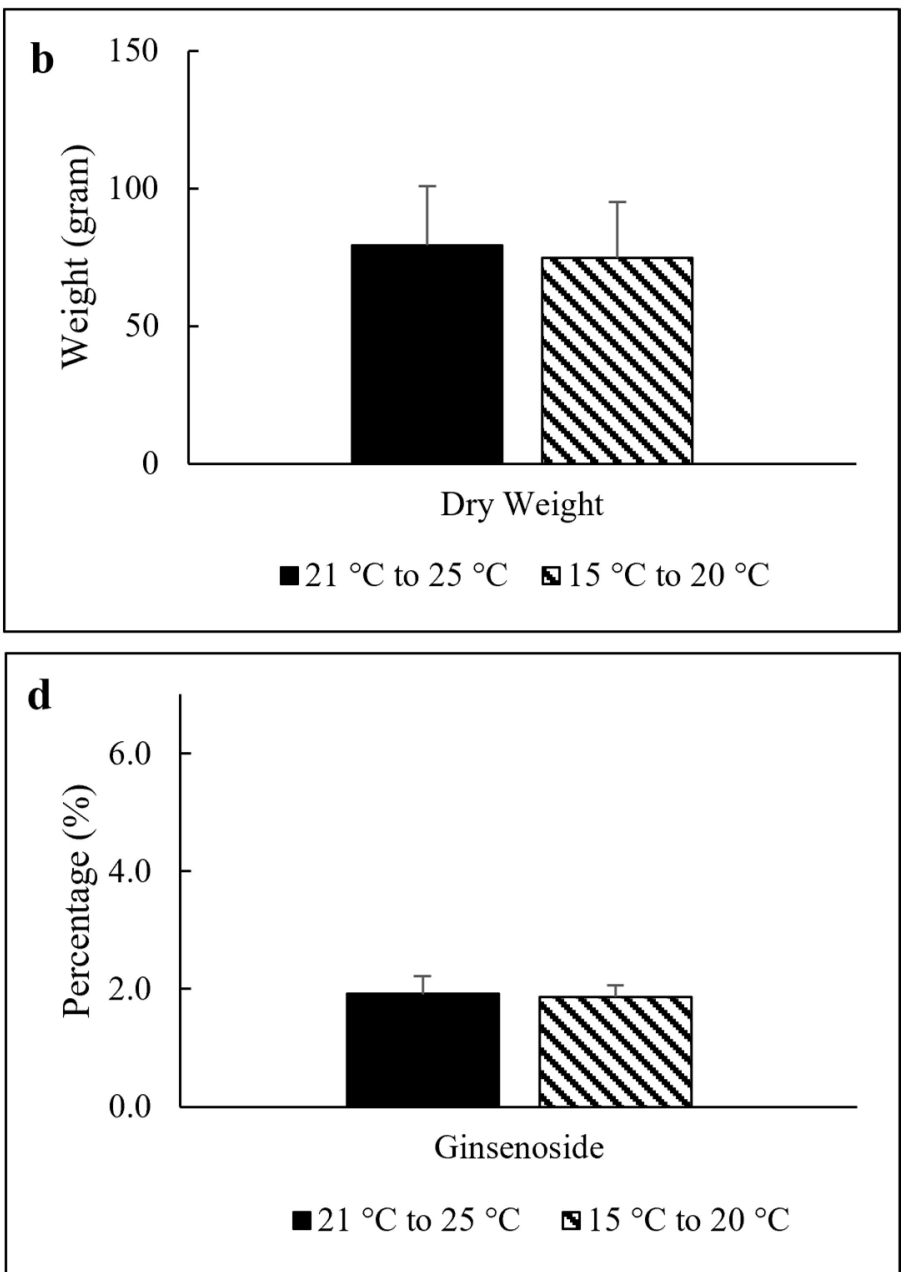

Figure 4: Bar chart of the effect of incubation temperature on a) fresh weight, b) dry weight, c) yield percentage and water content, and d) ginsenoside content. Values are means $\pm S D(n>3)$. Based on the One-Way ANOVA, the parameters showed no significantly different values for each variation $(P<0.05 \%)$. 
The fresh weights of the roots incubated at the temperatures of $21^{\circ} \mathrm{C}$ to $25^{\circ} \mathrm{C}$ and $15^{\circ} \mathrm{C}$ to $20^{\circ} \mathrm{C}$, were $1625.98 \mathrm{~g} \pm 333.591 \mathrm{~g}$ and $1461.65 \mathrm{~g} \pm 304.163 \mathrm{~g}$. The statistical analysis revealed that although the roots had higher fresh weight when incubated at $21^{\circ} \mathrm{C}$ to $25^{\circ} \mathrm{C}$ than $15^{\circ} \mathrm{C}$ to $20^{\circ} \mathrm{C}$, the difference between the two was not significant. This result corresponds to the study conducted by Wang et al. (2019), P. ginseng root growth and ginsenoside accumulation were optimal when incubated at $20{ }^{\circ} \mathrm{C}$ to $25^{\circ} \mathrm{C}$.

The dry weights of the roots incubated at the temperatures of $21^{\circ} \mathrm{C}$ to $25^{\circ} \mathrm{C}$ and $15{ }^{\circ} \mathrm{C}$ to $20{ }^{\circ} \mathrm{C}$ were $79.31 \mathrm{~g} \pm 21.442 \mathrm{~g}$ and $74.88 \mathrm{~g} \pm 20.154 \mathrm{~g}$. Based on the statistical analysis results, the root cultures had higher dry weight when incubated at $21{ }^{\circ} \mathrm{C}$ to $25^{\circ} \mathrm{C}$ than $15^{\circ} \mathrm{C}$ to $20^{\circ} \mathrm{C}$, but the difference between the two was not statistically significant. Nevertheless, this result was better than the previous studies that used a smaller bioreactor scale, which resulted in $0.150 \mathrm{~g}$ to $0.250 \mathrm{~g}$ dry weight after five weeks of culture on 1/2 MS media (Hwang et al., 1997; Yang et al., 1996).

The yield percentages produced by the incubation temperatures of $21{ }^{\circ} \mathrm{C}$ to $25^{\circ} \mathrm{C}$ and $15{ }^{\circ} \mathrm{C}$ to $20{ }^{\circ} \mathrm{C}$ were $4.85 \% \pm 0.578 \%$ and $5.09 \% \pm 0.563 \%$, while the water contents were $5.01 \% \pm 0.668 \%$ and $4.71 \%$ $\pm 0.490 \%$. The statistical analysis results showed that the yield percentage and water content between the incubation temperature ranges were not significantly different. The extracts of the roots incubated at $21^{\circ} \mathrm{C}$ to $25^{\circ} \mathrm{C}$ and $15^{\circ} \mathrm{C}$ to $20^{\circ} \mathrm{C}$ contained $1.87 \% \pm 0.030 \%$ and $1.91 \% \pm 0.019 \%$ ginsenosides. Based on the statistical analysis results, variation in the incubation temperature did not cause a significant difference in ginsenoside levels even though the roots contained more ginsenosides when incubated at $15{ }^{\circ} \mathrm{C}$ to $20{ }^{\circ} \mathrm{C}$ than $21{ }^{\circ} \mathrm{C}$ to $25{ }^{\circ} \mathrm{C}$. These results indicate that the incubation temperature of $15{ }^{\circ} \mathrm{C}$ to $20{ }^{\circ} \mathrm{C}$ can increase the accumulation of ginsenosides in the root extract. This can be associated with cold temperatures that potentially cause stress to the roots, which trigger them to produce bioactive compounds at higher levels (Wang et al., 2019). The analysis results of each parameter suggest that $21^{\circ} \mathrm{C}$ to $25^{\circ} \mathrm{C}$ was the optimal range of incubation temperature.

\section{Optimum growth condition of Panax ginseng root cultures}

The roots were produced in three production batches according to the identified optimal conditions for roots production. The conditions were as follows: $150 \mathrm{~g}$ fresh weight of roots as the inoculum, medium volume of $13 \mathrm{~L}$, the medium formulation "B", and 7 wk incubation at the temperature of $21{ }^{\circ} \mathrm{C}$ to $25^{\circ} \mathrm{C}$. Although using $14 \mathrm{~L}$ of medium growth effectively produces the desired results, this volume was not used because it required a different formulation. The results showed that the roots cultured in $14 \mathrm{~L}$ of medium prepared with formulation " $\mathrm{A}$ " had the highest weight among the combination of parameter values, but those grown in $13 \mathrm{~L}$ of medium with formulation "B" had a higher weight. The effects of applying optimum procedures to roots production on the fresh weight, dry weight, yield percentage, water content, and ginsenoside content are summarized in Table 1.

Table 1: Panax ginseng root culture profiles under optimum growth conditions.

\begin{tabular}{llll} 
Parameter & \multicolumn{3}{l}{ Mass Production Batch } \\
& Batch 1 & Batch 2 & Batch 3 \\
Fresh Weight (g) & $2954.12 \pm$ & $2628.11 \pm$ & $2870.32 \pm$ \\
& 95.034 & 97.609 & 105.483 \\
Dry Weight (g) & $124.68 \pm$ & $118.76 \pm$ & $122.52 \pm$ \\
& 4.515 & 3.107 & 6.677 \\
Yield (\%) & $4.22 \pm$ & $4.29 \pm$ & $4.27 \pm$ \\
& 0.130 & 0.241 & 0.108 \\
Water Content (\%) & $4.88 \pm$ & $5.15 \pm$ & $5.09 \pm$ \\
& 0.473 & 0.505 & 0.867 \\
Ginsenoside (\%) & $2.64 \pm$ & $3.01 \pm$ & $2.83 \pm$ \\
& 0.122 & 0.234 & 0.241
\end{tabular}

As seen in Table 1, the procedures used for root cultures successfully produced consistent fresh weight, dry weight, yield percentage, water content, and ginsenoside content. However, they still have some weaknesses leading to ginsenoside levels that are not as high as expected. The large-scale production needs to adopt other strategies, such as adding elicitors or applying stress conditions to increase the ginsenoside concentrations in the root cultures. Therefore, it is recommended that future research focuses on increasing ginsenoside levels while maintaining a high yield of roots biomass.

\section{Conclusions and Recommendations}

The optimal procedure for large-scale production of Panax ginseng root cultures is to inoculate as much as $150 \mathrm{~g}$ of roots into $13 \mathrm{~L}$ of growth medium with the formulation "B", followed by incubation at $21{ }^{\circ} \mathrm{C}$ to 
$25{ }^{\circ} \mathrm{C}$ for 7 wk. These procedures have successfully produced consistent data (root culture and extract properties) in three independent production batches.

\section{Acknowledgment}

This research was supported by PT. Bintang Toedjoe and the Matching Fund grant provided by the Ministry of Education, Culture, Research, and Technology of the Republic of Indonesia (No. 3122/ E3/PKS.08/KL/2021).

\section{Novelty Statement}

Among numerous plant tissue cultures, the root culture offers many advantages as it enables stable growth, is genetically stable, and can produce higher secondary metabolites. This is the first in vitro Panax ginseng root culture report in Indonesia. The initial stage of mass production focuses on optimizing the culture growth using variations in the factors, i.e., inoculum weight (100 g, $150 \mathrm{~g}$, and $200 \mathrm{~g}$ ), the media volume (12 L, $13 \mathrm{~L}$, and $14 \mathrm{~L})$, medium formulation ("A" and "B"), and incubation temperature $\left(15{ }^{\circ} \mathrm{C}\right.$ to $20^{\circ} \mathrm{C}$ and $21^{\circ} \mathrm{C}$ to $25^{\circ} \mathrm{C}$ ). Based on the biomass yield and ginsenoside contents, it can be concluded that the optimum growth conditions include the use of $150 \mathrm{~g}$ of initial inoculum, $13 \mathrm{~L}$ of growth medium prepared with the formulation "B", and incubation at a temperature of $21^{\circ} \mathrm{C}$ to $25^{\circ} \mathrm{C}$.

\section{Author's Contribution}

SPC: Performed the literature search, data acquisition, statistical analysis, and manuscript preparation.

YMV: Carried out experimental studies, performed literature search and data acquisition.

TLC: Performed data analysis and manuscript review. M Wongso and M Widjaja: Carried out experimental studies, data acquisition, and data analysis.

D-CY: Performed data analysis and manuscript review.

SCK: Elaborated the intellectual content and manuscript review.

MFMA: Elaborated the intellectual content and manuscript review.

JS: Conceptualized and designed the study, elaborated the intellectual content, performed literature search, manuscript review, manuscript revision and guarantor. All authors have read and approved the final manuscript.
Conflict of interest

The authors have declared no conflict of interest.

\section{References}

Adinurani, P.G. 2016. Design and analysis of agro trial data: Manual and SPSS. Plantaxia, Yogyakarta, Indonesia.

Akula, R. and G.A. Ravishankar, 2011. Influence of abiotic stress signals on secondary metabolites in plants. Plant Signal. Behav., 6(11): 17201731. https://doi.org/10.4161/psb.6.11.17613

Amir, M., M. Aqil, M.V. Ismail, M. Akhtar, A.H. Khan and M. Mujeeb. 2017. Effect of carbon source and incubation temperature on total content of secondary metabolites of callus culture of Solanum nigrum. World J. Pharm. Res., 6(8): 905-922. https://doi.org/10.20959/ wjpr20178-7306

Arifin, H., N. Anggraini, D. Handayani and R. Rasyid. 2006. Standardization of the ethanol extract of the Eugenia cumini Merr. leaves. J. Sains Tek. Far., 11(2): 88-93.

Baque, M.A., M.H.K. Shiragi, M. Sang-Hyun, E.J. Lee, and K.Y.Paek. 2013.Production of biomass and bioactive compounds by adventitious root suspension cultures of Morinda citrifolia (L.) in a liquid-phase airlift balloon-type bioreactor. In Vitro Cell Dev. Biol. Plant, 49(6): 737-749. https://doi.org/10.1007/s11627-013-9555-3

Christensen, L.P., M.Jensen and U. Kidmose. 2006. Simultaneous determination of ginsenosides and polyacetylenes in American ginseng root (Panax quinquefolium L.) by high-performance liquid chromatography. J. Agric. Food Chem., 54(24): 8995-9003. https://doi.org/10.1021/ jf062068p

Gantait, S., M. Mitra and J.T. Chen. 2020. Biotechnological interventions for ginsenosides production. Biomolecules, 10(4): 538, 1-17. https://doi.org/10.3390/biom10040538

Gulzar, B., A. Mujib, M.M. Qadir, J. Mamgain, R. Syeed and N. Zafar. 2020. Plant tissue culture: Agriculture and industrial applications. Chapter 2, p. 25-49. In: Transgenic technology based value addition in plant biotechnology, Academic Science, New York., https://doi. org/10.1016/B978-0-12-818632-9.00002-2

Hwang, B., K.M. Ko, D.C. Yang, J.C. Park, K.T. Choi. 1997. The enhancing method of ginsenoside production for hairy root mass 
cultures of Ginseng Panax ginseng CA. Meyer. In Biology of Root Formation and Development (pp. 325-325). Springer, Boston, MA. https:// doi.org/10.1007/978-1-4615-5403-5_70

Khan, A., A. Bashir, S. Erum, J.Z.K. Khatak, and A. Muhammad. 2021. Effects of 6-benzylaminopurine and indole-3-acetic acid on growth and root development of banana explants in micropropagation. Sarhad J. Agric., 37(1): 9-13. https://doi.org/10.17582/journal. sja/2021/37.1.9.13

Khan, U.W., R. Ahmed, I. Shahzadi and M.M. Shah. 2015. Some important factors influencing tissue culture response in wheat. Sarhad J.Agric., 31(4): 199-209. https://doi.org/10.17582/ journal.sja/2015/31.4.199.209

Kim, D.S., M. Song, S.H. Kim, D.S. Jang, J.B. Kim, B.K. Ha, S.H. Kim, K.J. Lee, S.Y. Kang and I.Y. Jeong. 2013. The improvement of ginsenoside accumulation in Panax ginseng as a result of $\gamma$-irradiation. J. Ginseng Res., 37(3): 332-340. https://doi.org/10.5142/jgr.2013.37.332

Kim, J.H. 2018. Pharmacological and medical applications of Panax ginseng and ginsenosides: a review for use in cardiovascular diseases. J. Ginseng Res., 42(3): 264-269. https://doi. org/10.1016/j.jgr.2017.10.004

Lech, K., A. Michalska, A. Wojdyło, P. Nowicka and A. Figiel.2017. The influence of the osmotic dehydration process on physicochemical properties of osmotic solution. Molecules, 22(12): 2246, 1-12. https://doi.org/10.3390/ molecules22122246

Lee,E.J.,M.Mobin,E.J.Hahn and K.Y.Paek. 2006. Effects of sucrose, inoculum density, auxins, and aeration volume on ceil growth of Gymnema sylvestre. J. Plant Biol., 49(6): 427-431. https:// doi.org/10.1007/BF03031122

Mahady, G.B., C. Gyllenhaal, H.H. Fong and N.R. Farnsworth. 2000. Ginsengs: A review of safety and efficacy. Nutr. Clin. Care, 3(2): 90-101. https://doi.org/10.1046/j.15235408.2000.00020.x

Manuhara, Y.S.W., A.N. Kristanti and E.S.W. Utami.2015. Optimization of culture conditions of Talinum paniculatum Gaertn. adventitious roots in balloon type bubble bioreactor using aeration rate and initial inoculum density. Asian J. Biol. Sci., 8(2): 83-92. https://doi. org/10.3923/ajbs.2015.83.92
Melviana, A.C., R.R. Esyanti, R.H. Setyobudi, M. Mel, P.G. Adinurani and J. Burlakovs. 2021a. Gene expression related to steviol glycoside synthesis produced in Stevia rebaudiana (Bert.) shoot culture induced with high Far-Red LED light in TIS RITA ${ }^{\circledR}$ bioreactor system. Sarhad J. Agric., 37(1): 1-8. https://doi.org/10.17582/ journal.sja/2021/37.1.1.8

Melviana, A.C., R.R. Esyanti, R.H. Setyobudi, M. Mel and R.H. Setyobudi. 2021b. Biomass enhancement of Stevia rebaudiana Bertoni shoot culture in temporary immersion system (TIS) RITA $^{\circledR}$ bioreactor optimized in two different immersion periods. E3S Web Conf.226(00007): 1-9. https://doi. org/10.1051/e3sconf/202122600007

Prinzenberg, A.E., H. Barbier, D.E. Salt, B. Stich and M. Reymond. 2010. Relationships between growth, growth response to nutrient supply, and ion content using a recombinant inbred line population in Arabidopsis. Plant Physiol., 154(3): 1361-1371. https://doi.org/10.1104/ pp.110.161398

Qi, L.W., C.Z.Wang and C.S. Yuan. 2011. Isolation and analysis of ginseng: Advances and challenges. Nat. Prod. Rep., 28(3): 467-495. https://doi.org/10.1039/c0np00057d

Sengupta, S., S.A. Toh, L.A. Sellers, J.N. Skepper, P. Koolwijk, H.W. Leung, H.W. Yeung, R.N. Wong, R. Sasisekharan, and T.P.D. Fan. 2004. Modulating angiogenesis: The yin and the yang in ginseng. Circulation, 110(10): 1219-1225. https://doi.org/10.1161/01. CIR.0000140676.88412.CF

Sevik, H. and K. Guney. 2013. Effects of IAA, IBA, NAA, and GA3 on rooting and morphological features of Melissa officinalis L. stem cuttings. Sci. World J., I.D.909507: 1-5. https://doi. org/10.1155/2013/909507

Smetanska, I. 2008. Production of secondary metabolites using plant cell cultures, $p$ 187-228. In: Stahl U., U.E. Donalies, and E. Nevoigt (eds), Advances in biochemical engineering/biotechnology, vol. 111, SpringerVerlag Berlin Heidelberg, https://doi. org/10.1007/10_2008_103

Srivastava, S. and Srivastava, A.K., 2007. Hairy root culture for mass-production of highvalue secondary metabolites. Crit. Rev. Biotechnol., 27(1): 29-43. https://doi. org/10.1080/07388550601173918 
Than, N.G., H.N. Murthy, K.W. Yu, C.S. Jeong, E.J. Hahn, K.Y. Paek. 2004. Effect of inoculum size on biomass accumulation and ginsenoside production by large-scale cell suspension cultures of Panax ginseng. J. Plant Biotechnol., 6(4): 265-268.

Vogl, J. and M. Ostermann. 2006. On the measurement of the moisture content in different matrix materials. Accreditation Qual. Assur., 11(7): 356-362. https://doi. org/10.1007/s00769-006-0159-z

Wang, S., W.X. Liang, L. Yao, J. Wang, W.Y. Gao. 2019. Effect of temperature on morphology, ginsenosides biosynthesis, functional genes, and transcriptional factors expression in Panax ginseng adventitious roots. J. Food Biochem., 43(4):1-10.https://doi.org/10.1111/jfbc.12794

Yang, D.C., H.Y. Choi, Y.H. Kim, K.Y. Yun. 1996.
Growth and ginsenosides production of hairy root (Panax ginseng CA Meyer) via light energy. Korean J. Ginseng Sci., 20(3): 318-324.

Young, J.M., L.D. Kuykendall, E. MartinezRomero, A. Kerr. and H. Sawada. 2001. A revision of Rhizobium Frank 1889, with an emended description of the genus, and the inclusion of all species of Agrobacterium Conn 1942 and Allorhizobium undicola de Lajudie et al. 1998 as new combinations: Rhizobium radiobacter, $R$. rhizogenes, $R$. rubi, $R$. undicola and R. vitis. Int. J. Syst. Evol., 51(1): 89-103. https://doi.org/10.1099/00207713-51-1-89

Yu, H., J. Zhao, J. You, J. Li, H. Ma and X. Chen. 2019. Factors influencing cultivated ginseng (Panax ginseng $\mathrm{CA}$ Meyer) bioactive compounds. PloS one, 14(0223763): 1-17. https://doi.org/10.1371/journal.pone.0223763 